\title{
Carbapenemase Genes among Multidrug Resistant Gram Negative Clinical Isolates from a Tertiary Hospital in Mwanza, Tanzania
}

\author{
Martha F. Mushi, ${ }^{1,2}$ Stephen E. Mshana, ${ }^{1}$ Can Imirzalioglu, ${ }^{3,4}$ and Freddie Bwanga \\ ${ }^{1}$ Department of Microbiology, Catholic University of Health and Allied Sciences, P.O. Box 1464, Mwanza, Tanzania \\ ${ }^{2}$ Department of Medical Microbiology, School of Biomedical Sciences, Makerere University College of Health Sciences, \\ P.O. Box 7072, Kampala, Uganda \\ ${ }^{3}$ Institute of Medical Microbiology, Justus-Liebig University, Schubertstraße 81, 35392 Giessen, Germany \\ ${ }^{4}$ German Centre for Infection Research (DZIF), Partner Site Giessen-Marburg-Langen, Campus, Giessen, Germany \\ ${ }^{5}$ MBN Clinical Laboratories, Plot 28 Nakasero Road, Kampala, Uganda
}

Correspondence should be addressed to Martha F. Mushi; marthamushi@yahoo.com

Received 5 November 2013; Revised 30 December 2013; Accepted 16 January 2014; Published 24 February 2014

Academic Editor: Branka Bedenic

Copyright (C) 2014 Martha F. Mushi et al. This is an open access article distributed under the Creative Commons Attribution License, which permits unrestricted use, distribution, and reproduction in any medium, provided the original work is properly cited.

\begin{abstract}
The burden of antimicrobial resistance (AMR) is rapidly growing across antibiotic classes, with increased detection of isolates resistant to carbapenems. Data on the prevalence of carbapenem resistance in developing countries is limited; therefore, in this study, we determined the prevalence of carbapenemase genes among multidrug resistant gram negative bacteria (MDR-GNB) isolated from clinical specimens in a tertiary hospital in Mwanza, Tanzania. A total of 227 MDR-GNB isolates were analyzed for carbapenem resistance genes. For each isolate, five different PCR assays were performed, allowing for the detection of the major carbapenemase genes, including those encoding the VIM-, IMP-, and NDM-type metallo-beta-lactamases, the class A KPC-type carbapenemases, and the class D OXA-48 enzyme. Of 227 isolates, 80 (35\%) were positive for one or more carbapenemase gene. IMP-types were the most predominant gene followed by VIM, in $49(21.59 \%)$ and $28(12 \%)$ isolates, respectively. Carbapenemase genes were most detected in K. pneumoniae 24 (11\%), followed by P. aeruginosa 23 (10\%), and E. coli with 19 isolates (8\%). We have demonstrated for the first time a high prevalence of MDR-GNB clinical isolates having carbapenem resistance genes in Tanzania. We recommend routine testing for carbapenem resistance among the MDR-GNB particularly in systemic infections.
\end{abstract}

\section{Introduction}

Carbapenem antibiotics have been used as the last resort salvage treatment for infections caused by multidrug resistancegram negative bacteria (MDR-GNB) [1], that is, gram negative bacteria resistant to at least three of the following antimicrobials: ampicillin, augmentin, ceftazidime, ciprofloxacin, gentamicin, and/or trimethoprim-sulfamethoxazole (SXT) [2]. Thus, resistance to carbapenems becomes a real threat to the survival of patients with infections caused by MDR-GNB, and the overall mortality in such infections has been reported to be up to $50 \%[3,4]$.

Resistance to carbapenems among the MDR-GNB is mostly due to the production of carbapenemases, which are $\beta$-lactamases with capacity to hydrolyze not only the carbapenems themselves but also all the other beta lactam agents [5]. Some of these carbapenemases include veron integron metallo-beta-lactamases, imipenemase, Klebsiella pneumoniae carbapenemases, oxacillinase-48, and New Delhi metallo-beta-lactamase_1 which are encoded by what is termed carbapenem resistance determining genes (CRDG): $b l a_{\mathrm{VIM}}, b l a_{\mathrm{IMP}}, b l a_{\mathrm{KPC}}, b l a_{\mathrm{OXA}-48}$, and $b l a_{\mathrm{NDM}}$, respectively [6].

Recently, increasing resistance to carbapenems in health care associated infections has been reported worldwide [1,7]. Studies in New York City found 39\% of patients with fecal colonization of KPC producing K. pneumoniae [3]. In Africa, data on the prevalence and distribution of carbapenem 
TABLE 1: Primer sets for amplification of carbapenem resistance determine genes (16).

\begin{tabular}{|c|c|c|c|}
\hline Gene & Primer sequence $\left(5^{\prime} \rightarrow 3^{\prime}\right)$ & $\mathrm{TM}\left({ }^{\circ} \mathrm{C}\right)$ & Amplicons size (bp) \\
\hline$b l a-_{\text {VIM }}$ & $\begin{array}{l}\text { Forward: GATGGTGTTTGGTCGCATA } \\
\text { Reverse: CGAATGCGCAGCACCAG }\end{array}$ & $\begin{array}{r}54.5 \\
57.6\end{array}$ & 390 \\
\hline$b l a-_{\mathrm{KPC}}$ & $\begin{array}{c}\text { Forward: CATTCAAGGGCTTTCTTGCTGC } \\
\text { Reverse: ACGACGGCATAGTCATTTGC }\end{array}$ & $\begin{array}{r}60.3 \\
57.3\end{array}$ & 498 \\
\hline$b l a{ }^{-} \mathrm{NDM}$ & $\begin{array}{l}\text { Forward: GGTTTGGCGATCTGGTTTTC } \\
\text { Reverse: CGGAATGGCTCATCACGATC }\end{array}$ & $\begin{array}{l}57.3 \\
59.4\end{array}$ & 521 \\
\hline$b l a-_{\text {IMP-1 }}$ & $\begin{array}{c}\text { Forward: TTGACACTCCATTTACAG } \\
\text { Reverse: GATTGAGAATTAAGCCACTCT }\end{array}$ & $\begin{array}{l}49.1 \\
54.0\end{array}$ & 232 \\
\hline$b^{b l a-}{ }_{\text {IMP-2 }}$ & $\begin{array}{c}\text { Forward: TTGACACTCCATTTACGG } \\
\text { Reverse: GATCGAGAATTAAGCCACCCT }\end{array}$ & $\begin{array}{r}51.4 \\
57.9\end{array}$ & 232 \\
\hline$b l a-{ }_{\text {IMP-3 }}$ & $\begin{array}{c}\text { TTGACACTCCATTTACTG } \\
\text { GATCGAGAATTAAGCCACTCT }\end{array}$ & $\begin{array}{l}49.1 \\
55.9\end{array}$ & 232 \\
\hline$b l a-$ OXA-48 & $\begin{array}{c}\text { Forward: GCTTGATCGCCCTCGATT } \\
\text { Reverse: GATTTGCTCCGTGGCCGAAA }\end{array}$ & $\begin{array}{r}56.0 \\
59.4\end{array}$ & 238 \\
\hline
\end{tabular}

TM: melting temperature of the primer.

resistance among the MDR-GNB is still limited. Few studies have been found to report on this problem; a surveillance study done in Kenya reported the recovery of seven NDM1-positive Klebsiella pneumoniae isolates mostly from urine samples [8]. While in two other studies the prevalence of metallo-beta-lactamase among Pseudomonas aeruginosa was reported to be $14 \%$ in Kenya [9] and 67\% in Northern Africa [10]. Other studies in South Africa reported the existence of carbapenemase producers among ESBL isolates $[4,11]$.

In this study, we determined a wide range of carbapenem resistance determining genes $\left(b l a_{\mathrm{VIM}}, b l a_{\mathrm{IMP}}, b l a_{\mathrm{KPC}}\right.$, $b l a_{\mathrm{OXA}-48}$, and $\left.b l a_{\mathrm{NDM}}\right)$ among different MDR-GNB isolates from patient specimens in Bugando Medical Centre-a tertiary hospital in Mwanza, Tanzania. All bacterial species which were resistant to three or more classes of antibiotics were regarded as MDR-GNB and included in the study.

\section{Materials and Methods}

2.1. Study Design and Population. This was a cross-sectional laboratory based study involving 234 multidrug resistant gram negative isolates collected between 2007 and 2012 from clinical specimens in a tertiary hospital, Northwestern, Tanzania. These isolates were from pus (112), urine (56), blood (55), aspirate (3), and sputum (1). The primary culture, identification using biochemical tests, and disk diffusion susceptibility testing of these isolates were done at Bugando Medical Centre following previously published techniques $[12,13]$. All the isolates had been confirmed to be resistant to ampicillin, and 177 (78\%) were ESBL producers as confirmed by double disk synergy test [13] and were frozen in brain heart infusion (BHI) broth with $20 \%$ glycerol at minus $80^{\circ} \mathrm{C}$ at the Microbiology Laboratory of Bugando Medical Centre.

2.2. Subculturing and Disk Diffusion Susceptibility Testing. Isolates were subcultured on blood agar (BA) and then resubjected to further susceptibility testing on Muller-Hinton agar to ampicillin $25 \mu \mathrm{g}$, amoxicillin/clavulanic acid $20 / 10 \mu \mathrm{g}$, ceftazidime $30 \mu \mathrm{g}$, ciprofloxacin $5 \mu \mathrm{g}$, gentamicin $10 \mu \mathrm{g}$, trimethoprim-sulfamethoxazole (TMP/SMX) 1.25/23.75 $\mu \mathrm{g}$, ertapenem $10 \mu \mathrm{g}$, and meropenem $10 \mu \mathrm{g}$ (Oxoid, UK). All susceptibility results were interpreted based on the CLSI 2010 guidelines [14].

2.3. PCR Amplification for Carbapenemase Genes. All the molecular/PCR tests (DNA extraction, amplification, and gel electrophoresis were conducted at MBN Clinical Laboratories, Kampala, Uganda. The presence of carbapenemase encoding genes was determined using primers targeting $b l a_{\mathrm{VIM}}, b l a_{\mathrm{IMP}}, b l a_{\mathrm{KPC}}, b l a_{\mathrm{OXA}-48}$, and $b l a_{\mathrm{NDM}}$ [15], obtained from Eurofin MWG Operon, Germany, as shown in Table 1. Cells were lysed using boiling method to obtain both genomic and plasmid DNA as described previously [16]. For amplification, $5 \mu \mathrm{L}$ of template DNA $(50 \mathrm{ng} / \mu \mathrm{L})$ was added to a $45 \mu \mathrm{L}$ mixture containing $200 \mu \mathrm{M}$ of dNTP mixtures (Roche, Switzerland), $0.4 \mu \mathrm{M}$ of each primer, $2.5 \mathrm{U}$ Taq polymerase (Invitrogen, Germany), and appropriate buffer $\left(0.2 \mu \mathrm{M} \mathrm{MgCl}_{2}, 2.5 \mu \mathrm{M} \mathrm{KCL}, 0.5 \mu \mathrm{L} 10 \%\right.$ Tween $20,1 \mu \mathrm{L}$ of Gelatin, and $3.8 \mu \mathrm{L}$ of pure water).

The amplification was done using GTQ-CYCLER 96 thermocycler machine (Hain Life science GmbH, Nehren, Germany). For $b l a_{\mathrm{VIM}}, b l a_{\mathrm{KPC}}, b l a_{\mathrm{NDM}}$, and $b l a_{\mathrm{OXA}-48}$, the programme was denaturation at $94^{\circ} \mathrm{C}$ for 45 seconds, annealing at $52^{\circ} \mathrm{C}$ for 1 minute, and elongation at $72^{\circ} \mathrm{C}$ for a minute. For $b l a_{\mathrm{IMP}}$ the same programme was used except that the annealing temperature was adjusted to $45^{\circ} \mathrm{C}$ for 60 seconds. The cycles were repeated 40 times and all primer sets had a final extension of $72^{\circ} \mathrm{C}$ for 10 minutes.

Five micro liters of PCR products were analyzed by electrophoresis in $1.0 \%$ agarose stained with ethidium bromide to detect the specific amplified product by comparing with 100 base-pairs standard DNA ladder (Promega, German). Quality control was performed with each run using DSMZ 9377 Klebsiella pneumoniae as the negative control for all genes. Positive control strains from the Institute of Microbiology, Giessen, Germany, were Klebsiella pneumonia Nr.8 for NDM-1, Klebsiella pneumoniae 714 for OXA-48, Klebsiella pneumoniae 211 (T) for KPC, and P. aeruginosa from clinical 
TABLE 2: Clinical isolate by specimens studied.

\begin{tabular}{|c|c|c|c|c|c|c|}
\hline \multirow{2}{*}{ Bacteria spp. } & \multicolumn{5}{|c|}{ Specimen } & \multirow{2}{*}{ Total } \\
\hline & Aspirate & Blood & Pus swab & Sputum & Urine & \\
\hline K. pneumoniae & 1 & 23 & 28 & 0 & 24 & 76 \\
\hline E. coli & 1 & 8 & 31 & 1 & 15 & 56 \\
\hline P. aeruginosa & 1 & 16 & 22 & 0 & 2 & 41 \\
\hline C. freundii & 0 & 1 & 8 & 0 & 6 & 15 \\
\hline A. baumannii & 0 & 2 & 8 & 0 & 0 & 10 \\
\hline P. vulgaris & 0 & 0 & 7 & 0 & 0 & 7 \\
\hline E. cloacae & 0 & 3 & 0 & 0 & 2 & 5 \\
\hline M. morganii & 0 & 0 & 2 & 0 & 1 & 3 \\
\hline P. mirabilis & 0 & 0 & 1 & 0 & 1 & 2 \\
\hline S. marcescens & 0 & 2 & 4 & 0 & 3 & 9 \\
\hline Salmonella typhi & 0 & 0 & 0 & 0 & 1 & 1 \\
\hline Salmonella spp. & 0 & 0 & 1 & 0 & 1 & 2 \\
\hline Total & 3 & 55 & 112 & 1 & 56 & 227 \\
\hline
\end{tabular}

TABLE 3: Resistance pattern of bacteria species used in the study.

\begin{tabular}{|c|c|c|c|c|c|c|c|c|c|}
\hline Isolate & AMP & AMC & $\mathrm{CRO}$ & CAZ & $\mathrm{CN}$ & $\mathrm{CP}$ & SXT & ERT & MEM \\
\hline A. baumannii (10) & $100.0 \%$ & $100.0 \%$ & $90.0 \%$ & $90.0 \%$ & $80.0 \%$ & $40.0 \%$ & $90.0 \%$ & $40.0 \%$ & $10.0 \%$ \\
\hline C. freundii (15) & $100.0 \%$ & $100.0 \%$ & $60.0 \%$ & $80.0 \%$ & $80.0 \%$ & $26.7 \%$ & $86.7 \%$ & $13.3 \%$ & $0.0 \%$ \\
\hline E. $\operatorname{coli}(56)$ & $100.0 \%$ & $100.0 \%$ & $84.0 \%$ & $82.1 \%$ & $73.2 \%$ & $44.6 \%$ & $96.4 \%$ & $19.6 \%$ & $8.9 \%$ \\
\hline Enterobacter (5) & $100.0 \%$ & $100.0 \%$ & $20.0 \%$ & $40.0 \%$ & $60.0 \%$ & $20.0 \%$ & $100.0 \%$ & $20.0 \%$ & $0.0 \%$ \\
\hline K. oxytoca (8) & $100.0 \%$ & $100.0 \%$ & $100.0 \%$ & $100.0 \%$ & $100.0 \%$ & $62.5 \%$ & $100.0 \%$ & $12.5 \%$ & $0.0 \%$ \\
\hline K. pneumoniae (68) & $100.0 \%$ & $98.5 \%$ & $84.0 \%$ & $79.4 \%$ & $83.8 \%$ & $33.8 \%$ & $97.1 \%$ & $16.2 \%$ & $1.5 \%$ \\
\hline M. morganii (3) & $100.0 \%$ & $100.0 \%$ & $33.3 \%$ & $33.3 \%$ & $33.3 \%$ & $0.0 \%$ & $100.0 \%$ & $0.0 \%$ & $0.0 \%$ \\
\hline P. aeruginosa (41) & $100.0 \%$ & $97.5 \%$ & $73.2 \%$ & $53.7 \%$ & $31.7 \%$ & $17.1 \%$ & $92.7 \%$ & $56.1 \%$ & $19.5 \%$ \\
\hline P. mirabilis (2) & $100.0 \%$ & $100.0 \%$ & $100.0 \%$ & $100.0 \%$ & $50.0 \%$ & $100.0 \%$ & $100.0 \%$ & $50.0 \%$ & $0.0 \%$ \\
\hline P. vulgaris (7) & $100.0 \%$ & $85.7 \%$ & $57.1 \%$ & $42.9 \%$ & $57.1 \%$ & $14.3 \%$ & $85.7 \%$ & $14.3 \%$ & $0.0 \%$ \\
\hline S. marcescens (9) & $100.0 \%$ & $100.0 \%$ & $66.7 \%$ & $66.7 \%$ & $66.7 \%$ & $44.4 \%$ & $100.0 \%$ & $0.0 \%$ & $0.0 \%$ \\
\hline Salmonella spp. (3) & $100.0 \%$ & $100.0 \%$ & $100.0 \%$ & $100.0 \%$ & $100.0 \%$ & $0.0 \%$ & $100.0 \%$ & $0.0 \%$ & $0.0 \%$ \\
\hline Total & $100.0 \%$ & $98.7 \%$ & $78.0 \%$ & $74.0 \%$ & $65.6 \%$ & $33.5 \%$ & $95.2 \%$ & $24.2 \%$ & $6.6 \%$ \\
\hline
\end{tabular}

AMP, AMC, CAZ, CRO, CN, CIP, SXT, ERT, and MEM stand for ampicillin, amoxicillin/clavulanic acid, ceftazidime, gentamicin, ciprofloxacin, trimethoprimsulfamethoxazole, ertapenem, and meropenem, respectively.

routine samples for IMP in Giessen. For the VIM gene, the control strain was obtained from RESET research collaboration [17].

2.4. Ethical Issues. The study was approved by the school of biomedical sciences research and ethics committee of Makerere University College of Health Sciences. Material transfer agreement for transportation of 234 isolates from Mwanza, Tanzania, to Kampala, Uganda, was obtained from the director of research and publication Catholic University of Health and Allied Sciences, Bugando.

\section{Results}

3.1. Clinical Bacterial Isolates Studied. The study excluded 9 isolates which failed to grow on subculture. Of the remaining 227 isolates which successfully grew, 76 (33.5\%) were $K$. pneumoniae as the most predominant species followed by E. coli $56(24.7 \%)$ and $P$. aeruginosa 41 (18.1\%) (Table 2 ).
The study used isolates which were resistant to at least three different classes of antibiotics; most of them were resistance to ampicillin $100 \%$, augmentin, and ceftazidime (Table 3 ). For this study, strains displaying breakpoints for either resistance or intermediate levels for ertapenem and meropenem were considered as reduced susceptible. Of the 227 MDR-GNB, 55 (24\%) had reduced susceptibility to ertapenem while only 15 (7\%) had reduced susceptibility to meropenem.

3.2. Prevalence of Carbapenemase Genes. Based on the PCR assays, 80 (35.24\%) of 227 MDR-GNB isolates were positive for one or more of the carbapenemase genes. Of the 55 isolates with reduced susceptibility to ertapenem, $33(60 \%)$ tested positive for carbapenemase genes $(P$ value $<0.001)$ while $11(73 \%)$ of the 15 isolates with reduced susceptibility to meropenem were positive for carbapenemase genes $(P$ value $=0.001$ ).

Overall, IMP-types were the most predominant carbapenemase genes detected in 49 (21.6\%), followed by VIM 
TABLE 4: Distribution of carbapenemase genes among different organisms studied.

\begin{tabular}{|c|c|c|c|c|c|c|}
\hline \multirow{2}{*}{ Bacterial spp. } & \multicolumn{6}{|c|}{ Carbapenemase genes } \\
\hline & IMP_types & VIM & OXA_48 & KPC & NDM & Carbapenemase positive \\
\hline A. baumannii (10) & 3 & 0 & 0 & 0 & 0 & 3 \\
\hline C. freundii (15) & 2 & 1 & 1 & 0 & 0 & 4 \\
\hline E. $\operatorname{coli}(56)$ & 19 & 4 & 3 & 4 & 2 & 32 \\
\hline E. cloacae (5) & 0 & 0 & 0 & 0 & 0 & 0 \\
\hline K. oxytoca (8) & 3 & 0 & 1 & 0 & 1 & 5 \\
\hline K. pneumoniae (68) & 9 & 11 & 4 & 3 & 2 & 29 \\
\hline M. morganii (3) & 0 & 0 & 0 & 0 & 1 & 1 \\
\hline P. aeruginosa (41) & 12 & 9 & 2 & 1 & 1 & 25 \\
\hline P. mirabilis (2) & 0 & 0 & 0 & 0 & 0 & 0 \\
\hline P. vulgaris (7) & 0 & 0 & 0 & 0 & 0 & 0 \\
\hline S. marcescens (9) & 0 & 2 & 0 & 0 & 0 & 2 \\
\hline \multirow[t]{2}{*}{ Salmonella spp. (3) } & 1 & 1 & 0 & 0 & 0 & 2 \\
\hline & 49 & 28 & 11 & 8 & 7 & 103 \\
\hline
\end{tabular}

TABLE 5: Antimicrobial susceptibility profile of isolates with multiple carbapenem resistance genes.

\begin{tabular}{lccccccccccc}
\hline & Isolate & CAZ & CRO & AMC & AMP & CN & CIP & ERT & MEM & SXT & Carbapenemase genes \\
\hline 1 & K. pneumoniae & $\mathrm{R}$ & $\mathrm{R}$ & $\mathrm{R}$ & $\mathrm{R}$ & $\mathrm{R}$ & $\mathrm{S}$ & $\mathrm{R}$ & $\mathrm{S}$ & $\mathrm{R}$ & KPC, IMP, VIM \\
2 & E. coli & $\mathrm{R}$ & $\mathrm{R}$ & $\mathrm{R}$ & $\mathrm{R}$ & $\mathrm{S}$ & $\mathrm{R}$ & $\mathrm{R}$ & $\mathrm{R}$ & $\mathrm{R}$ & KPC, IMP \\
3 & K. pneumoniae & $\mathrm{R}$ & $\mathrm{R}$ & $\mathrm{R}$ & $\mathrm{R}$ & $\mathrm{R}$ & $\mathrm{S}$ & $\mathrm{S}$ & $\mathrm{S}$ & $\mathrm{R}$ & OXA_48 and VIM \\
4 & P. aeruginosa & $\mathrm{R}$ & $\mathrm{R}$ & $\mathrm{R}$ & $\mathrm{R}$ & $\mathrm{S}$ & $\mathrm{S}$ & $\mathrm{R}$ & $\mathrm{S}$ & $\mathrm{R}$ & IMP_C and VIM \\
5 & E. coli & $\mathrm{R}$ & $\mathrm{R}$ & $\mathrm{R}$ & $\mathrm{R}$ & $\mathrm{R}$ & $\mathrm{R}$ & $\mathrm{S}$ & $\mathrm{S}$ & $\mathrm{R}$ & KPC and IMP \\
6 & K. pneumoniae & $\mathrm{R}$ & $\mathrm{R}$ & $\mathrm{R}$ & $\mathrm{R}$ & $\mathrm{R}$ & $\mathrm{R}$ & $\mathrm{S}$ & $\mathrm{S}$ & $\mathrm{R}$ & IMP and VIM \\
7 & K. pneumoniae & $\mathrm{R}$ & $\mathrm{R}$ & $\mathrm{R}$ & $\mathrm{R}$ & $\mathrm{R}$ & $\mathrm{S}$ & $\mathrm{S}$ & $\mathrm{S}$ & $\mathrm{R}$ & IMP and VIM \\
8 & E. coli & $\mathrm{R}$ & $\mathrm{R}$ & $\mathrm{R}$ & $\mathrm{R}$ & $\mathrm{R}$ & $\mathrm{R}$ & $\mathrm{S}$ & $\mathrm{S}$ & $\mathrm{R}$ & IMP and VIM \\
9 & E. coli & $\mathrm{R}$ & $\mathrm{R}$ & $\mathrm{R}$ & $\mathrm{R}$ & $\mathrm{R}$ & $\mathrm{R}$ & $\mathrm{S}$ & $\mathrm{S}$ & $\mathrm{R}$ & OXA_48, IMP \\
10 & E. coli & $\mathrm{R}$ & $\mathrm{R}$ & $\mathrm{R}$ & $\mathrm{R}$ & $\mathrm{R}$ & $\mathrm{S}$ & $\mathrm{R}$ & $\mathrm{S}$ & $\mathrm{R}$ & OXA_48 and NDM \\
11 & E. coli & $\mathrm{R}$ & $\mathrm{R}$ & $\mathrm{R}$ & $\mathrm{R}$ & $\mathrm{S}$ & $\mathrm{S}$ & $\mathrm{S}$ & $\mathrm{S}$ & $\mathrm{R}$ & VIM and NDM \\
12 & K. pneumoniae & $\mathrm{R}$ & $\mathrm{R}$ & $\mathrm{R}$ & $\mathrm{R}$ & $\mathrm{R}$ & $\mathrm{R}$ & $\mathrm{R}$ & $\mathrm{S}$ & $\mathrm{R}$ & OXA_48 and VIM \\
13 & E. coli & $\mathrm{R}$ & $\mathrm{R}$ & $\mathrm{R}$ & $\mathrm{R}$ & $\mathrm{R}$ & $\mathrm{R}$ & $\mathrm{R}$ & $\mathrm{R}$ & $\mathrm{R}$ & IMP and VIM \\
14 & C. freundii & $\mathrm{R}$ & $\mathrm{R}$ & $\mathrm{R}$ & $\mathrm{R}$ & $\mathrm{R}$ & $\mathrm{S}$ & $\mathrm{S}$ & $\mathrm{S}$ & $\mathrm{R}$ & OXA_48, IMP and VIM \\
15 & K. oxytoca & $\mathrm{R}$ & $\mathrm{R}$ & $\mathrm{R}$ & $\mathrm{R}$ & $\mathrm{R}$ & $\mathrm{S}$ & $\mathrm{R}$ & $\mathrm{S}$ & $\mathrm{R}$ & OXA_48 and NDM \\
\hline
\end{tabular}

$28(12.3 \%)$, OXA-48 $11(4.9 \%)$, KPC 8 (3.5\%), and NDM 7 (3.1\%) (Table 4$)$. These genes were either solitarily detected in one bacterial isolate or with more than one gene in one bacterial isolate. Of 80 bacterial isolates with carbapenemase genes, $15(6.6 \%)$ harbored more than one carbapenemase gene (Table 5).

\subsection{Distribution of Carbapenemase Genes among Multidrug} Resistant Gram Negative Bacterial Isolates. The genes were heterogeneously distributed among the different species of multidrug resistant gram negative bacteria with some bacteria species having more than one carbapenemase genes as shown in Table 5. E. coli was the most prevalent species with carbapenemase genes 32 (14\%), followed by Klebsiella pneumoniae 24 (10.57\%), P. aeruginosa 10.13\%, Klebsiella oxytoca $1.76 \%$, Acinetobacter baumannii $1.3 \%$, Citrobacter freundii $0.88 \%$, Serratia marcescens $0.88 \%$, and Salmonella spp. $0.44 \%$ (Table 4). Of the clinical specimens studied, carbapenemase genes were more prevalent in urine cultures $22(39.29 \%)$ of 56 specimens followed by blood culture 20 (36.36\%) of 55 specimen and pus swab with 37 (33.04\%) of 112 specimen studied.

\section{Discussion}

We detected a high prevalence (35.24\%) of carbapenemase genes among multidrug resistant gram negative bacterial species. The majority of the studied isolates were ESBL producer; thus, our results are similar to those obtained by Coetzee and Brink in South Africa [11]. This is a rather worrying finding in the poor populations in the horn of Africa; however, this data is comparable to study done in India which found a similar prevalence, particularly of MBL (NDM_1, VIM types, and IMP types) among family 
Enterobacteriaceae. In their study the prevalence of MBL was between $31 \%$ and $55 \%$ among multidrug resistant family Enterobacteriaceae [18]. This prevalence is in concordance with another study obtained in India which reported the prevalence of carbapenemase genes among gram negative bacterial isolates to be $43 \%[19,20]$. On the other hand, this magnitude is a bit higher than data reported from USA and Kenya [9, 21]; this could be explained by the fact that those studies investigated fewer genes than in the current study.

In the current study, we also detected 22 bacterial species with phenotypically reduced susceptibility to carbapenem drugs but its resistance mechanisms were not detected by any of the screened carbapenemase primers used in this study. This might be due to the limited number of genes targeted in our study as well as to other mechanisms of resistance such as porin loss/mutations [22, 23].

As previously published, OXA-48 gene for carbapenem resistance has been found in ESBL producers especially those harboring CTX-M [24]. This was also proved in this study as most of OXA- 48 gene was detected on CTX-M producing $K$. pneumoniae and E. coli $[25,26]$.

In comparison with other carbapenem-resistant genes $b l a_{\mathrm{VIM}}$ poses the broadest range of substrate hydrolysis and can eventually degrade all $\beta$-lactam except monobactams [27]. In the present study, these genes were mostly detected in K. pneumoniae, E. coli, and P. aeruginosa. This data corresponds to the findings of a study done in Korea where VIM was reported as the most predominant carbapenemase genes in class B metallo-beta-lactamase among gram negative clinical isolates. It also corresponds to the worldwide findings where VIM is reported as the commonest MBL to be found [28].

We have also detected a low prevalence $(n=7 / 3.08 \%)$ of NDM gene among multidrug-resistant gram negative bacteria. This prevalence is much lower than the one reported in India by Kumarasamy et al. among convenience sample of family Enterobacteriaceaein which they obtained a prevalence of $31 \%$ to $55 \%$ [18]. Plasmids carrying carbapenemase genes like NDM-1 are diverse and can harbor a high number of additional resistance genes (e.g., ESBL-alleles) as well as other carbapenemase genes like Oxacillinase-48 types, VIM types, and so forth, as the source of multidrug resistance in one single bacteria [18, 29]. Of 80 bacterial species detected of having carbapenemase genes, 15 had multiple genes coding for carbapenem resistance especially in E. coli and $P$. aeruginosa. The presence of multiple resistance genes in one strain provides selection advantage of these strains [26]. This phenomenon has not been commonly detected in a large number of studies probably due to the number of genes studied since most of the studies research on one or two genes.

The study did not investigate the clonality of the isolates and the sequence of the genes and also did not use primers to target all known carbapenemases genes. Thus, there is a probability that some carbapenemase-producing isolates could not be adequately characterized. Despite these limitations, the study has provided the distribution of the common carbapenemase genes and the magnitude of the problem.

\section{Conclusion and Recommendation}

We have, for the first time, demonstrated a high prevalence of carbapenem-resistance conferring genes among multidrug resistant gram negative bacteria in Tanzania. Most of the isolates harboring carbapenemase genes originated from blood culture specimens and pus. We recommend routine testing for carbapenem resistance among the MDR-GNB in our hospital and other health facilities in developing countries where there is high prevalent MDR GNB. In addition, other antibiotics such as colistin and tigecycline should be tested to provide alterative treatment to these isolates. More studies should be done to determine evolution and molecular epidemiology of these isolates.

\section{Conflict of Interests}

The authors declare that there is no conflict of Interests regarding the publication of this paper.

\section{Acknowledgments}

The authors would like to acknowledge the technical support provided by the members of the Department of Microbiology/Immunology of CUHAS-Bugando, Mwanza, Tanzania, and MBN clinical laboratory, Kampala, Uganda. This work was supported by a research grant of ITECH, Tanzania, and CUHAS to Martha F. Mushi, reagents from SACIDS to Stephen E. Mshana, and a researcher startup grant of the Faculty of Medicine of the Justus-Liebig-University Giessen to Can Imirzalioglu.

\section{References}

[1] O. Moquet, C. Bouchiat, A. Kinana et al., "Class D OXA-48 carbapenemase in multidrug-resistant enterobacteria, Senegal," Emerging Infectious Diseases, vol. 17, no. 1, pp. 143-144, 2011.

[2] A. E. Pop-Vicas and E. M. C. D’Agata, “The rising influx of multidrug-resistant gram-negative bacilli into a tertiary care hospital," Clinical Infectious Diseases, vol. 40, no. 12, pp. 17921798, 2005.

[3] S. Bratu, D. Landman, R. Haag et al., "Rapid spread of carbapenem-resistant Klebsiella pneumoniae in New York City: a new threat to our antibiotic armamentarium," Archives of Internal Medicine, vol. 165, no. 12, pp. 1430-1435, 2005.

[4] A. J. Brink, J. Coetzee, C. G. Clay et al., "Emergence of New Delhi metallo-beta-lactamase (NDM-1) and Klebsiella pneumoniae carbapenemase (KPC-2) in South Africa," Journal of Clinical Microbiology, vol. 50, no. 2, pp. 525-527, 2012.

[5] A. M. Queenan and K. Bush, "Carbapenemases: the versatile $\beta$-lactamases," Clinical Microbiology Reviews, vol. 20, no. 3, pp. 440-458, 2007.

[6] P. Nordmann, T. Naas, and L. Poirel, "Global spread of carbapenemase producing Enterobacteriaceae," Emerging Infectious Diseases, vol. 17, no. 10, pp. 1791-1798, 2011.

[7] A. Carrër, L. Poirel, M. Yilmaz et al., "Spread of OXA-48encoding plasmid in Turkey and beyond," Antimicrobial Agents and Chemotherapy, vol. 54, no. 3, pp. 1369-1373, 2010. 
[8] L. Poirel, G. Revathi, S. Bernabeu, and P. Nordmann, "Detection of NDM-1-producing Klebsiella pneumoniae in Kenya," Antimicrobial Agents and Chemotherapy, vol. 55, no. 2, pp. 934-936, 2011.

[9] J. D. D. Pitout, G. Revathi, B. L. Chow et al., "Metallo- $\beta$ lactamase-producing Pseudomonas aeruginosa isolated from a large tertiary centre in Kenya," Clinical Microbiology and Infection, vol. 14, no. 8, pp. 755-759, 2008.

[10] S. Hammami, I. Boutiba-Ben Boubaker, R. Ghozzi, M. Saidani, S. Amine, and S. Ben Redjeb, "Nosocomial outbreak of imipenem-resistant Pseudomonas aeruginosa producing VIM-2 metallo- $\beta$-lactamase in a kidney transplantation unit," Diagnostic Pathology, vol. 6, no. 1, article 106, 2011.

[11] J. Coetzee and A. Brink, "The emergence of carbapenem resistance in Enterobacteriaceae in South Africa," Southern African Journal of Epidemiology and Infection, vol. 26, no. 4, pp. 239240, 2011.

[12] N. Kayange, E. Kamugisha, D. L. Mwizamholya, S. Jeremiah, and S. E. Mshana, "Predictors of positive blood culture and deaths among neonates with suspected neonatal sepsis in a tertiary hospital, Mwanza-Tanzania," BMC Pediatrics, vol. 10, article 39, 2010.

[13] S. E. Mshana, E. Kamugisha, M. Mirambo, T. Chakraborty, and E. F. Lyamuya, "Prevalence of multiresistant gram-negative organisms in a tertiary hospital in Mwanza, Tanzania," BMC Research Notes, vol. 2, article 49, 2009.

[14] CLSI, Standards for Antimicrobial Disk Susceptibility Tests. Approved Standard, Document M2-A9, Clinical and Laboratory Standards Institute, Wayne, Pa, USA, 9th edition, 2010.

[15] C. Dallenne, A. da Costa, D. Decré, C. Favier, and G. Arlet, "Development of a set of multiplex PCR assays for the detection of genes encoding important $\beta$-lactamases in Enterobacteriaceae," Journal of Antimicrobial Chemotherapy, vol. 65, no. 3, pp. 490-495, 2010.

[16] D. S. Holmes and M. Quigley, "A rapid boiling method for the preparation of bacterial plasmids," Analytical Biochemistry, vol. 114, no. 1, pp. 193-197, 1981.

[17] J. Fischer, I. Rodríguez, S. Schmoger et al., "Escherichia coli producing VIM-1 carbapenemase isolated on a pig farm," Journal of Antimicrobial Chemotherapy, vol. 67, no. 7, pp. 17931795, 2012.

[18] K. K. Kumarasamy, M. A. Toleman, T. R. Walsh et al., "Emergence of a new antibiotic resistance mechanism in India, Pakistan, and the UK: a molecular, biological, and epidemiological study," The Lancet Infectious Diseases, vol. 10, no. 9, pp. 597-602, 2010.

[19] J. D. D. Pitout, D. B. Gregson, L. Poirel, J.-A. McClure, P. Le, and D. L. Church, "Detection of Pseudomonas aeruginosa producing metallo- $\beta$-lactamases in a large centralized laboratory," Journal of Clinical Microbiology, vol. 43, no. 7, pp. 3129-3135, 2005.

[20] A. M. Hammerum, M. A. Toleman, F. Hansen et al., "Global spread of New Delhi metallo- $\beta$-lactamase 1," The Lancet Infectious Diseases, vol. 10, no. 12, pp. 829-830, 2010.

[21] C. Lascols, M. Hackel, S. H. Marshall et al., "Increasing prevalence and dissemination of NDM- 1 metallo- $\beta$-lactamase in India: data from the SMART study (2009)," Journal of Antimicrobial Chemotherapy, vol. 66, no. 9, pp. 1992-1997, 2011.

[22] P. Nordmann, L. Dortet, and L. Poirel, "Carbapenem resistance in Enterobacteriaceae: here is the storm!," Trends in Molecular Medicine, vol. 18, no. 5, pp. 263-272, 2012.
[23] D. P. Webster, T. Gaulton, N. Woodford et al., "Emergence of carbapenem resistance due to porin loss in an extendedspectrum $\beta$-lactamase (ESBL)-producing Klebsiella pneumoniae strain during meropenem therapy," International Journal of Antimicrobial Agents, vol. 36, no. 6, pp. 575-576, 2010.

[24] A. Potron, L. Poirel, E. Rondinaud, and P. Nordmann, "Intercontinental spread of OXA-48 beta-lactamase-producing Enterobacteriaceae over a 11-year period, 2001 to 2011," Euro Surveillance, vol. 18, no. 31, Article ID 20549, 2013.

[25] S. E. Mshana, C. Imirzalioglu, T. Hain, E. Domann, E. F. Lyamuya, and T. Chakraborty, "Multiple ST clonal complexes, with a predominance of ST131, of Escherichia coli harbouring blaCTX-M-15 in a tertiary hospital in Tanzania," Clinical Microbiology and Infection, vol. 17, no. 8, pp. 1279-1282, 2011.

[26] S. E. Mshana, T. Hain, E. Domann, E. F. Lyamuya, T. Chakraborty, and C. Imirzalioglu, "Predominance of Klebsiella pneumoniae ST14 carrying CTX-M-15 causing neonatal sepsis in Tanzania," BMC Infectious Diseases, vol. 13, no. 1, article 466, 2013.

[27] J.-D. Docquier, J. Lamotte-Brasseur, M. Galleni, G. Amicosante, J.-M. Frère, and G. M. Rossolini, "On functional and structural heterogeneity of VIM-type metallo- $\beta$-lactamases," Journal of Antimicrobial Chemotherapy, vol. 51, no. 2, pp. 257-266, 2003.

[28] N. Gupta, B. M. Limbago, J. B. Patel, and A. J. Kallen, "Carbapenem-resistant Enterobacteriaceae: epidemiology and prevention," Clinical Infectious Diseases, vol. 53, no. 1, pp. 6067, 2011.

[29] P. Nordmann, L. Poirel, M. A. Toleman, and T. R. Walsh, “Does broad-spectrum $\beta$-lactam resistance due to NDM- 1 herald the end of the antibiotic era for treatment of infections caused by Gram-negative bacteria?" Journal of Antimicrobial Chemother$a p y$, vol. 66, no. 4, pp. 689-692, 2011. 

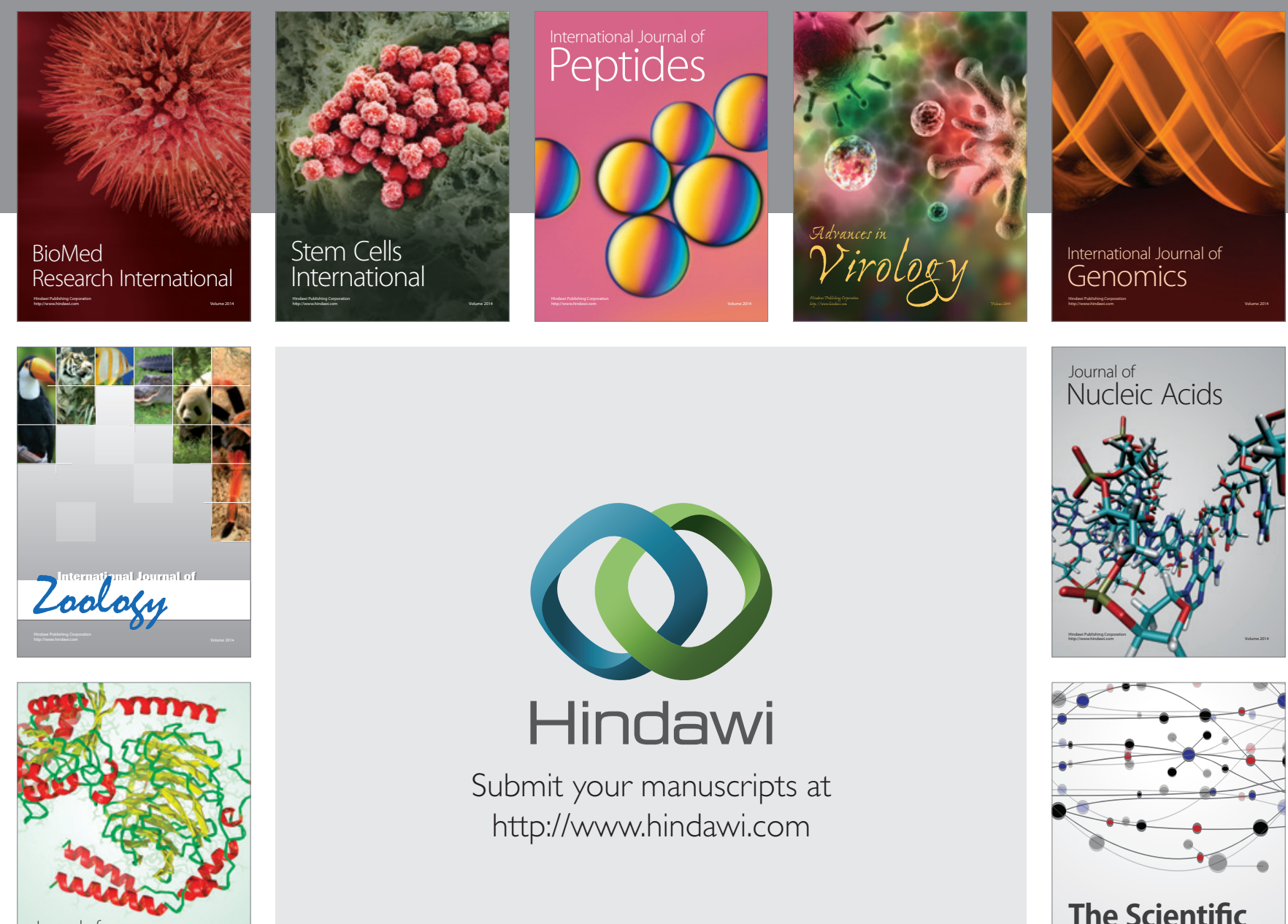

Submit your manuscripts at

http://www.hindawi.com

Journal of
Signal Transduction
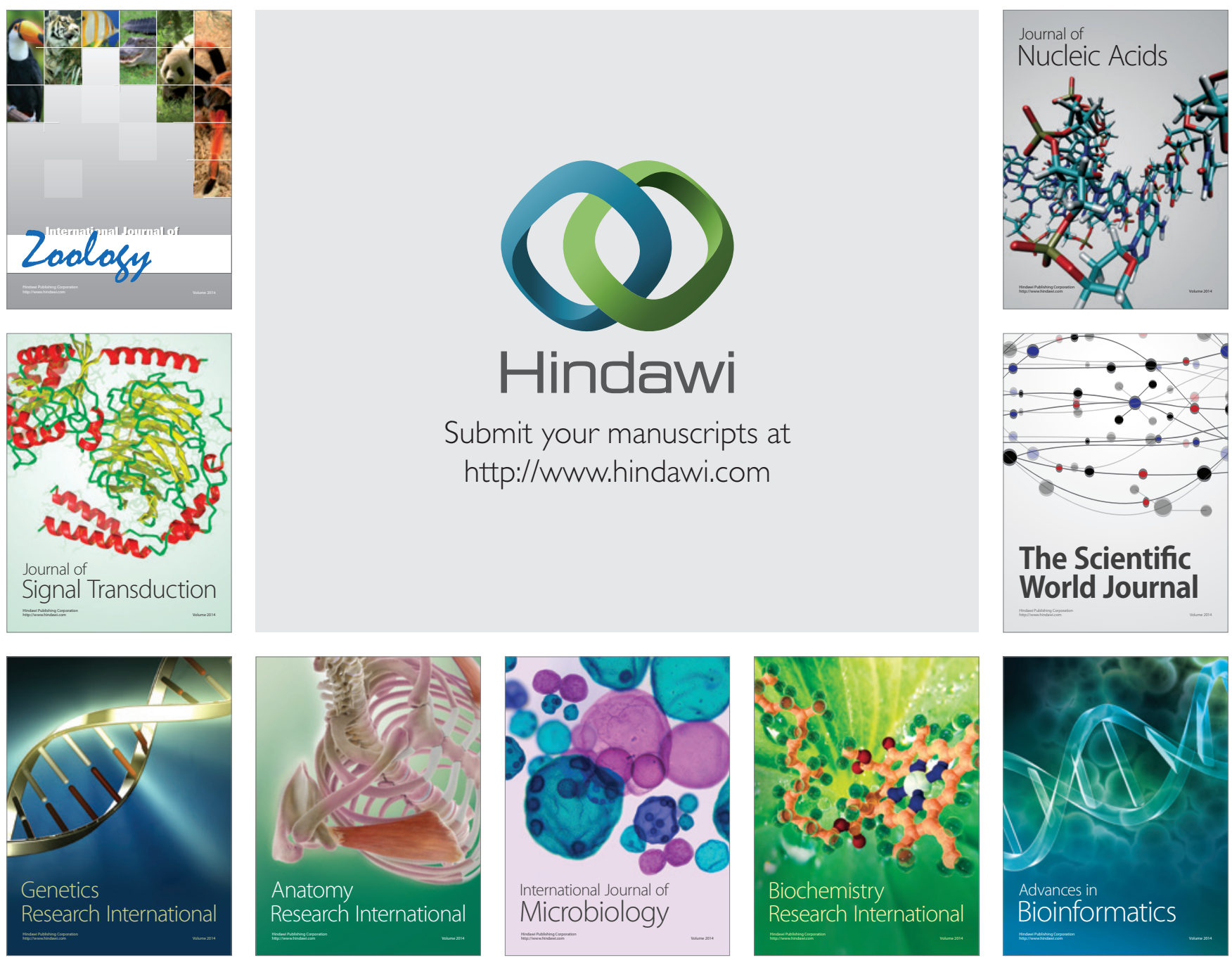

The Scientific World Journal
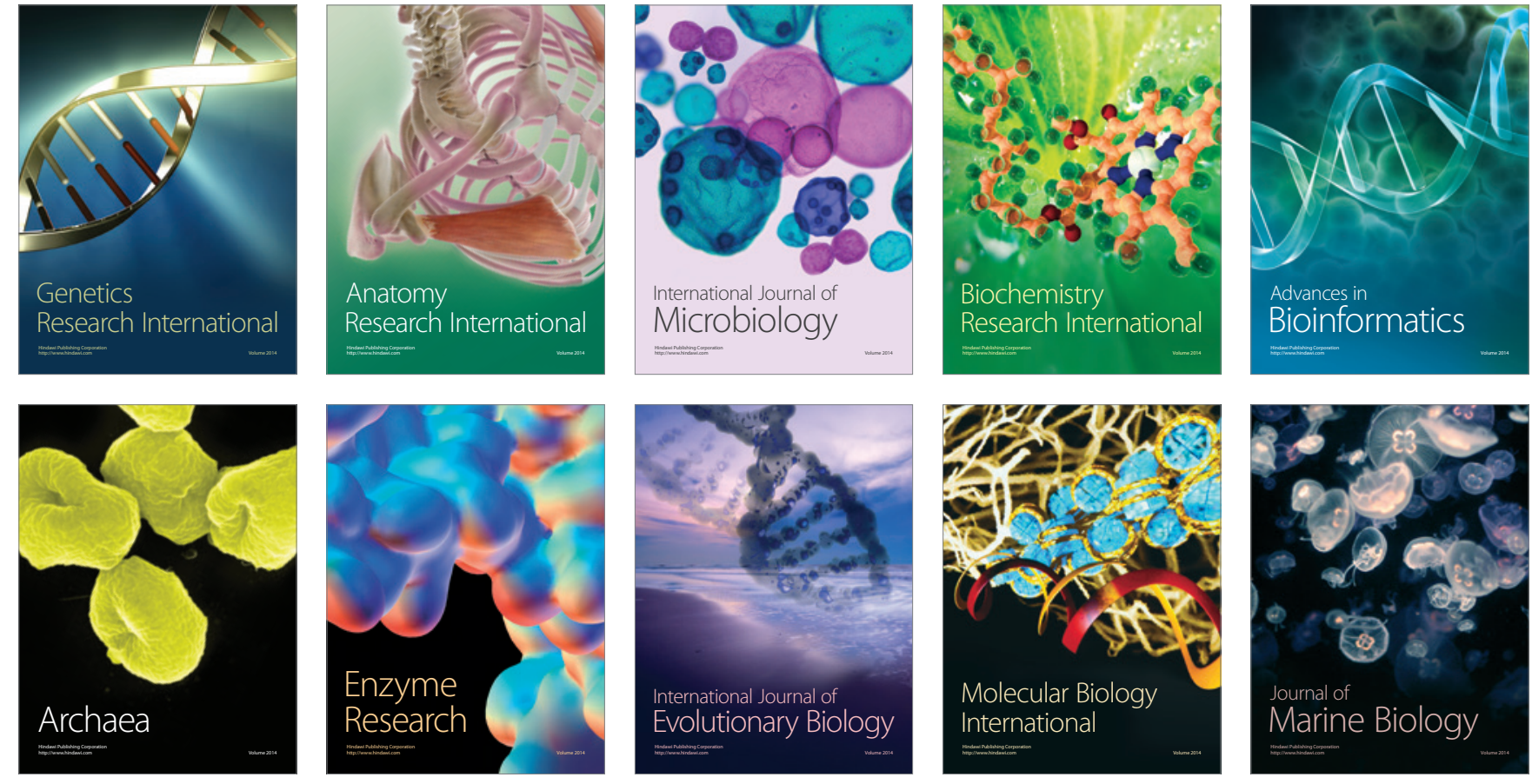